\title{
LA ENSEÑANZA DE LA HISTORIA Y EL USO DE LIBROS DE TEXTO ANTE LOS RETOS DEL SIGLO XXI. ENTREVISTA A RAFAEL VALLS MONTÉS
}

\author{
History Education and the use of textbooks into the challenges \\ of twenty fist century. Interview with Rafael Valls Montés
}

\section{Cosme J. Gómez Carrasco ${ }^{\varnothing}$ y Raimundo A. Rodríguez Pérez ${ }^{\S}$}

Resumen. La entrevista a Rafael Valls Montés aborda la importancia del manual escolar en la enseñanza de la historia. Es el recurso didáctico más empleado tanto en Educación Primaria como Secundaria en España. El Dr. Valls es quien más ha estudiado su uso por parte del profesorado, contenidos y actividades. A partir de un diálogo permanente con los avances historiográficos y psicopedagógicos (España, Europa y América) y el contexto político, el manual muestra una evolución a grandes rasgos positiva. Desde la década de 1970 viene influenciado por la idea de historia total, de la Escuela de Annales, con la inclusión de contenidos políticos, sociales, económicos y culturales. Sin embargo, aún sigue marcado por numerosos estereotipos, de tipo factual y positivista, que lastran su utilidad. Además, contribuye a una escasa innovación en las metodologías docentes empleadas (reducidas a lección magistral) y convierte al estudiante en un receptor pasivo, que debe memorizar cuestiones conceptuales. La otra gran rémora del manual escolar es su función esencialmente creadora de identidades: española, europea y, en menor medida, autonómica. Una herencia de los nacionalismos decimonónicos, que no se ajusta la realidad multicultural de la sociedad, reflejada en las aulas. Con todo, el manual es fruto del espíritu de las sucesivas leyes educativas y, aunque mute su formato, seguirá siendo un recurso esencial para enseñar y aprender historia.

\footnotetext{
" Este artículo es resultado de los proyectos de investigación EDU2015-65621-C3-2-R «La evaluación de las competencias y el desarrollo de capacidades cognitivas sobre historia en Educación Secundaria Obligatoria» y EDU2014-51720-REDT RED 14 «Red de investigación en enseñanza de las ciencias sociales», financiados por el Ministerio de Economía y Competitividad.

${ }^{\circ}$ Departamento de Didáctica de las Ciencias Matemáticas y Sociales. Facultad de Educación. Universidad de Murcia. Campus de Espinardo.30100 Espinardo (Murcia).cjgomez@um.es.

$\S$ Departamento de Didáctica de las Ciencias Matemáticas y Sociales. Facultad de Educación. Universidad de Murcia. Campus de Espinardo. 30100 Espinardo (Murcia).raimundorodriguez@um.es.
}

Cómo citar este artículo: Gómez Carrasco, Cosme J. y Rodríguez Pérez, Raimundo A. «La enseñanza de la historia y el uso de libros de texto ante los retos del siglo XxI. Entrevista a Rafael Valls Montés», Historia y Memoria de la Educación, 6 (2017): 363-380. 
Por tanto, debe servir como estímulo para una educación cívica e innovadora.

Palabras clave: Manual escolar; Enseñanza de la historia; Historiografía; Metodología docente; Educación cívica.

Abstract. The interview with Rafael Valls Montés addresses the importance of the textbook in teaching history. It is the most-used didactic resource in both Primary and Secondary Education in Spain. Dr. Valls is the specialist who has most studied the use of textbooks by teachers as well as their contents and activities. With an eye constantly on historiographical and psycho-pedagogical advances (Spain, Europe and America) and political context, the overall evolution can be considered positive. Since the 1970s, the creation of textbooks has been influenced by the idea of "total history", of the Annales School, with the inclusion of political, social, economic and cultural contents. However, school textbooks are still marked by numerous stereotypes, both factual and positivist, that detract from their usefulness. In addition, they tend to contribute to a lack of innovation in the teaching methodologies employed (reduced to lectures), resulting in students' becoming passive receivers, obliged to memorize conceptual questions. The other great drawback of the school manual is that it essentially functions as a creator of identities: Spanish, European and, to a lesser extent, regional. This derives from a legacy of nineteenth-century nationalisms, which do not fit the multicultural reality of society as reflected in today's classrooms. However, the manual is ultimately the result of the spirit of a succession of educational laws and, although its format may change it is bound to remain an essential resource for teaching and learning history. Moreover, it should serve as a stimulus for civic and innovative education.

Keywords: Textbook; History Education; Historiography; Teaching methodology; Civic education.

Con demasiada frecuencia la Historia, como materia formativa, ha estado sujeta a los intereses del poder más que a fines puramente instructivos. El uso público de la Historia en la creación de identidades sociales, políticas y culturales ha estado muy unido al nacimiento de los Estados-nación en el siglo XIX, y todavía sigue teniendo gran vigencia por su uso y abuso por parte de nacionalismos centrífugos y centrípetos. Afortunadamente han sido muchos los docentes e investigadores que se han resistido y han luchado contra estos objetivos puramente identitarios. Unos objetivos que olvidan la capacidad formativa de la historia para el desarrollo de destrezas complejas de pensamiento, de análisis, de síntesis, y en la creación de una conciencia histórica y social 
basada en una educación cívica y ciudadana. El Dr. Rafael Valls Montés (Catedrático de Didáctica de las Ciencias Sociales en el Departamento de Didáctica de las Ciencias Experimentales y Sociales de la Universidad de Valencia) es uno de estos grandes docentes e investigadores que han dedicado buena parte de su vida a reivindicar la historia como materia formativa, y a analizar y reflexionar sobre los discursos e imágenes estereotipadas que habitan esas herramientas tan usadas en la clase de historia: los libros de texto. Efectivamente, el análisis de los manuales escolares desde una perspectiva global ha sido una de sus principales líneas de investigación (análisis diacrónicos, análisis temáticos y de contenido, análisis de las actividades y su carga pedagógica, o análisis de las imágenes que contienen). Pero el Dr. Rafael Valls también ha dedicado gran parte de sus investigaciones a la configuración histórica de esta disciplina escolar, y a la conexión de las finalidades de la enseñanza de la Historia con la construcción de identidades colectivas en sus diversas dimensiones (nacionales, europeas, mediterráneas, iberoamericanas e interculturales).

El Dr. Rafael Valls fue profesor de Educación Secundaria entre 19761991, un momento de época dorada para los grupos de innovación docente en historia (13-16, Germanía 75, etc.). Sin duda estos años de experiencia en Educación Secundaria fueron claves para entender las investigaciones realizadas posteriormente. En ese año 1991 comienza como Profesor Titular de Escuela Universitaria en la Escuela de Magisterio de la Universidad de Valencia. En el año 1996 pasa a ser Profesor Titular de Universidad, y en 2008 como Catedrático de Didáctica de las Ciencias Sociales en la Universidad de Valencia. Una trayectoria profesional que debe complementarse con la dirección y participación de diversos proyectos de investigación impulsados por diferentes instituciones españolas, europeas e iberoamericanas; su colaboración con el Instituto Georg Eckert de Brunswick (Alemania) en las investigaciones que ha impulsado el Consejo de Europa sobre la enseñanza de la historia; su participación en el grupo de investigadores integrantes del Proyecto MANES, dedicado al estudio de los manuales escolares españoles e iberoamericanos (UNED); y su pertenencia al grupo de investigación DHIGECS de la Universidad de Barcelona, dirigido por el Dr. Joaquim Prats. 
Fruto de esa dilatada trayectoria profesional el Dr. Rafael Valls ha desarrollado una gran producción científica. Muestra de ello son su más de cien artículos, libros, capítulos de libro y conferencias impartidas en congresos nacionales e internacionales. Sus primeras obras versaron sobre la interpretación de la historia en el franquismo a través de los planes de estudio, así como estudios específicos sobre la Guerra Civil y el papel de los partidos políticos valencianos en su desarrollo. La amplitud de temáticas abordadas a partir del año 1995 sobre la enseñanza de la historia, el uso de libros de texto y la construcción de identidades sociales y políticas, así como su capacidad de síntesis le han permitido publicar en una gran variedad de revistas científicas de impacto nacional e internacional. De esta forma, destacan sus artículos en revistas de didáctica de las ciencias sociales de España e Iberoamérica (Íber. Didáctica de las Ciencias Sociales, Geografía e Historia; Didáctica de las Ciencias Experimentales y Sociales; Enseñanza de las Ciencias Sociales. Revista de Investigación; Clío \& Asociados. La Historia enseñada; Revista de Teoría y Didáctica de las Ciencias Sociales; Con-ciencia social: anuario de didáctica de la geografía, la historia y las ciencias sociales,...); revistas de ciencias de la educación (Aula de Innovación Educativa; Praxis educativa; Aula de historia social; Alambique: revista de didáctica de las ciencias experimentales; Cuadernos de Pedagogía; Historia de la Educación: revista interuniversitaria; Revista de Educación y Pedagogía,...); y revistas de historia, historiografía e historia contemporánea (Gerónimo de Uztariz, Bulletin d'histoire contemporaine de l'Espagne; Pasajes: revista de pensamiento contemporáneo; Histoire \& Sociétés. Revue européenne d'histoire social; L'Avenç: revista de historia y cultural,...).

En su labor científica cabe destacar también su capacidad formativa, con la dirección de varias tesis doctorales, la coordinación de un grupo de investigación en la Universidad de Valencia, donde se integran investigadores como Xosé Manuel Souto, Jorge Sáiz, David Parra o Juan Carlos Colomer. Una labor de gestión que el Dr. Rafael Valls ha complementado con la dirección y pertenencia al comité científico de revistas de impacto nacional e internacional. Así, es director de la revista Didáctica de las ciencias experimentales y sociales de la Universidad de Valencia, desde 1993, y es miembro del Consejo científico de revistas como Enseñanza de las Ciencias Sociales. Revista de investigación, desde el año 2002; Le Cartable de Clio (Suiza), desde el año 2005; Clio \& Asociados (Argenti- 
na), desde 2005; Íber. Didáctica de las Ciencias Sociales, Geografía e Historia, desde el año 2007; y Mundus. Revista de Didattica Della Storia (Italia), desde el año 2008.

El Dr. Rafael Valls es una persona imprescindible de conocer, leer y escuchar, dado su amplio bagaje investigador y docente. Tan dilatada experiencia lo avala como una de las principales figuras del área de Didáctica de las Ciencias Sociales en España. No se puede abordar un análisis de libros de texto de historia, una reflexión sobre la enseñanza de la historia en España, o el papel de esta materia formativa en la construcción de identidades sociales, políticas y culturales en Iberoamérica sin recurrir a sus textos. Por ello es tan importante conocer en profundidad su experiencia en esta área de conocimiento desde una entrevista personal, en la que se aborden tanto sus reflexiones académicas como sus preocupaciones y esperanzas por el futuro de esta disciplina científica.

\section{1. ¿Por qué un entonces joven profesor de Secundaria como usted} decidió investigar sobre la enseñanza de la historia de España en el franquismo? Es decir, ¿cómo llega a la disciplina didáctica y no a una salida a priori más natural, por ejemplo la historia contemporánea?

Preferí — era el año 1975- dedicarme a la Enseñanza Secundaria por varios motivos. En primer lugar, mayor libertad de acción y poco interés, incluso rechazo, a trabajar en la universidad. Conocía a un profesor que acababa de acceder a la figura de Catedrático de Educación Secundaria (Alfons Ginés), muy interesado en dicha etapa educativa, que me introdujo en la enseñanza-innovación educativa. Así entré en contacto y colaboré con grupos como Germanía 75, Garbí y Llavors. El tema de la tesina de licenciatura (la enseñanza de la historia de España en el primer franquismo) vino después (1980), pues deseaba probarme como investigador individual, uniendo la didáctica de la Historia con la investigación histórica. De ahí a los manuales fue casi una ocurrencia, aunque la idea me llegó a través de un colega del instituto de bachillerato. Luego ya contacté en Italia con el GEI: el Georg Eckert Institut für internationale Schulbuchforschung, el más destacado centro mundial, aunque estuviese radicado en Alemania, para la investigación sobre los manuales escolares de historia (ya son unos más de treinta años de colaboración) y el 
proyecto Emmanuelle, el proyecto francés más destacado en relación al conjunto de los manuales escolares franceses, que sería imitado, poco después, en España, mediante el importantísimo proyecto Manes, que aún sigue vigente y del que soy colaborador desde su inicio, también allá por los años noventa.

\section{2. ¿Cuáles son los déficits y las fortalezas que observa en la enseñanza de la historia en España y en el resto del mundo?}

La enseñanza de la Historia es algo complicado. En cuanto a los avances, los ha habido teóricos y prácticos. Las didácticas específicas o aplicadas (Historia, Geografía, Historia del Arte y otras más) se inician en la década de 1960, especialmente en los Estados Unidos de América y, en España, como área de conocimientos universitarios, en la década de 1980. A partir de ese momento llegarían las influencias extranjeras: Francia, Italia, Gran Bretaña, algo de Alemania,... Después vendría el influjo de EE. UU., Canadá, etc. Y los didactas españoles nos proyectaríamos y colaboraríamos posteriormente en Iberoamérica. Los pocos conocimientos previos a la década de 1980 darían pie, con muchas lecturas, a la eclosión de los grupos innovadores, muy importantes y numerosos en España, durante ese decenio y el siguiente.

Respecto a los déficits, destacaría la persistencia del «código disciplinar» y las rutinas, es decir, la preeminencia de los usos tradicionales en la enseñanza de la historia y su consideración como formas «naturales» o ahistóricas de su enseñanza y aprendizaje. En segundo lugar, el boicot administrativo, con la imposición e incremento de programas enciclopédicos. El PSOE intentó dejarlo atrás en la década de 1990, pero la ofensiva conservadora le hizo retroceder, excepto en las declaraciones iniciales de los currícula, que son aceptables y posibilitadoras de lecturas y practicas diversas, el resto es pura tradición mala. En el resto de países occidentales ocurre más o menos lo mismo, al darse una gran separación entre la didáctica y la práctica docente. De forma mayoritaria, con todas sus excepciones, se ha producido una regresión a situaciones previas y un escaso minoritarismo innovador, que no va más allá del diez-quince por ciento del profesorado (son datos extraídos a partir de lo que denominamos el uso escolar de los materiales didácticos alternativos en las aulas escolares españolas). 
3. A menudo los investigadores nos centramos en las propuestas que provienen del ámbito anglosajón (principalmente de Inglaterra, EE. UU. y Canadá). Sin embargo hay paradigmas interesantes que provienen del ámbito alemán o francés que suelen obviarse ¿Cree que este déficit proviene del desconocimiento lingüístico o que tiene también otras causas?

Sí, al menos en el caso alemán, el francés es muy distinto. Tendríamos que haber hecho un esfuerzo mayor en las informaciones y traducciones alemanas, por ejemplo de Jörn Rüsen y de algunos otros afamados e importantes autores alemanes. En los últimos veinte años, que yo conozca, sólo se ha traducido: un artículo de Rüsen (en la revista Íber. Didáctica de las Ciencias Sociales, Geografía e Historia, 1997) y un artículo mío sobre la didáctica de la Historia alemana (en la misma revista, 1999). Algunas obras de Rüsen (entre otros alemanes) están en inglés y sobre todo en portugués (editadas en Curitiba, Brasil). Esto provoca falsas atribuciones en lo del "pensar históricamente», por ejemplo, o en la relación didáctica de la Historia y sus finalidades socio-políticas y culturales. Sin ir más lejos, la equivocada percepción angloamericanista de la «conciencia histórica», en la reciente tesis de Carlos Fuster (Universidad de Valencia, 2016), que critiqué por tal motivo en su presentación pública.

Lo francés ha estado más presente, al menos en los investigadores de mi generación: Nicole Tutiaux, Henri Moniot François Audigier y muchos otros. También los estudiosos de la Historia, de la Historia enseñada (Nicole Lautier, Annie Brutter, Suzanne Citron Evelyne Hery, etc.). Asimismo en los manuales de Historia, a través del proyecto Emmanuelle y de su director Alain Choppin y el conjunto de su equipo investigador. Los italianos estuvieron también parcialmente presentes: Scipione Guarracino, Ivo Matozzi, Antonio Brusa o Luigi Cajani. Pero ya todos se hicieron mayores y la didáctica de la Historia italiana ha perdido presencia y el escaso poder académico, que nunca tuvo realmente.

Sois las generaciones más recientes de investigadores de la Didáctica de la Historia, junto con algunos «seniors», los que habéis potenciado a los teóricos anglosajones más recientes, pues a los más prácticos del proyecto del School Council ya los conocíamos desde los primeros años ochenta (de eso se encargaron, entre otros, los catalanes de grupo 13-16, Joaquim Prats y Joan Santacana entre los principales, y los valencianos, 
principalmente Pilar Maestro y su grupo Kairós, aunque esto último fuese unos años más tarde). Eso es importante, pero tendríamos que atender también a los europeos y de otros contextos, por ejemplo África, América Latina, Extremo Oriente (Japón, Corea, China), que son importantes, siempre que la lengua nos lo permita.

4. Sin cambios legislativos que afecten de verdad a los decretos enciclopédicos, ¿cree que puede abandonarse el abuso de los manuales y metodologías tradicionales de enseñanza de la historia en la educación obligatoria?

Los cambios legislativos, al menos en lo referido a los programas y contenidos factuales, superando el enfoque enciclopédico, ayudaría sin duda a generar un profesorado menos atado a tales programas y, por tanto, a los manuales. Pero no sería suficiente, y dudo que tal cambio se dé pues unos y otros están por la «nacionalización» de la sociedad en el sentido tradicional. Pero tampoco gran parte del profesorado estaría por esa labor: el código disciplinar es muy potente y sus consecuencias educativas se consideran "naturales», aunque sean, obviamente, socio-históricas, pero eso no viene considerado de esa manera, lo cual es tremendamente desafortunado y grave si nos estamos refiriendo a docentes versados en los saberes históricos.

Sabemos que el $90 \%$ del profesorado de Primaria y Secundaria usa los manuales con mayor o menor intensidad (un $70 \%$ con fuerte intensidad, casi exclusividad). Los manuales han mejorado, sin duda, pero aún tienen deficiencias claras: la escasa presencia de la multiperspectividad y la multimodalidad en su presentación de la Historia (la tesis doctoral de Jorge Sáiz -Universidad de Valencia, 2015- aborda esto con perfecta claridad). Y en las actividades que proponen existe una baja exigencia cognitiva (cuestión también tratada por Jorge Sáiz, Virginia Gámez, de la Universidad de Barcelona, y el Grupo DICSO de la Universidad de Murcia).

La escasa preparación didáctica del profesorado de Secundaria también ha sido cómplice o provocadora de esta situación y ello refuerza la persistencia de una visión trasnochada de las finalidades escolares de la enseñanza-aprendizaje de la historia. Los manuales están más actualizados - a pesar de la persistencia de estereotipos y no plena actualiza- 
ción- que gran parte del profesorado en ejercicio. En este sentido los manuales aportan mejores conocimientos históricos que los habituales en un profesorado que se actualiza o recicla poco, pues tampoco se le suministran estímulos externos ni existe una exigencia seria por parte de la administración.

\section{En la era de internet y la globalización, ¿qué función cree que debe} tener el docente de historia en los niveles educativos obligatorios?

Internet es una herramienta que puede ofrecer información amplísima sobre todo, aunque no toda ella sea «fiable». Las TIC también ofrecen alternativas de uso, comunicación y actividades interesantes y baratas. Eso puede beneficiar tanto a nuestros docentes como los investigadores (el acceso a muchas publicaciones sin apenas esfuerzo ni dinero). De ahí que, en lo que afecta al profesorado, su función primordial sería dedicarse a lo que internet no profundiza, esto es, impulsar y generar pensamiento histórico y conciencia histórica: esa es la posibilidad y el reto.

6. A menudo se suele exponer la historia de España como una sucesión de oportunidades perdidas para la modernidad y el progreso: Al Ándalus, el primer imperio global, los ilustrados, el Trienio Liberal, las dos Repúblicas... ¿coincide con esta visión en cierto modo "noventayochista»?

No, no comparto esa visión "noventayochista», pero tampoco me satisface la de la "plena normalidad» española en los siglos XIX y XX, tesis que ahora no tiene tanta presencia como hace diez o veinte años en la historiografía. Este país ha tenido momentos y personas o situaciones en ambas orientaciones, aunque ha sufrido una damnatio memoriae, por ejemplo en lo concerniente a la ILE (la Institución Libre de Enseñanza) y sus logros educativo-culturales tanto para los varones como para las mujeres (residencia de señoritas y su modernidad). La dictadura franquista hizo mucho daño y duró, como mínimo, hasta la muerte del dictador. Esa etapa no entraría, desde luego, en la «normalidad» modernizadora-europeísta ni lo más mínimo. Así lo escribió Borja de Riquer y yo comparto su síntesis: España un país «normal», pero bastante menos. 
7. El manual escolar como narrativa histórica, a pesar de sus carencias, ha contribuido a reforzar una visión nacionalista de la historia de España. ¿Cuál es el futuro de dicho recurso didáctico? ¿Podrá evolucionar para ser un verdadero epítome que sugiera retos e interrogantes atractivos para el alumnado?

Los manuales de Historia van a durar mucho, en soporte tradicional o digital. Su uso no ha decaído, sino que ha aumentado. Los manuales evolucionarán si los docentes evolucionan y son capaces de generar una «demanda escolar» diferente a la actual. Las editoriales estudian muy bien el mercado existente y saben adecuarse a la demanda (en eso les va el negocio). La doble apuesta, con métodos tradicionales e innovadores, que se dio durante las décadas de 1980 y 1990, ya se acabó. Los materiales «alternativos» sólo existen por ciclos y on line: languidecen y se mueren. ¿Qué ha pasado? Sería una buena tesis: «Cénit y ocaso de la innovación española en los manuales escolares de Historia». No pierdo las esperanzas, pero los tiempos futuros no son muy halagüeños.

8. En relación a lo anterior, es llamativo que por ejemplo un estudiante crea que Requena pertenece a Valencia desde la noche de los tiempos, o que en Murcia se deje a un lado la historia medieval y moderna de Orihuela y la Vega Baja del Segura por considerarla algo exógeno. Ante unos docentes que tampoco han estudiado esos contenidos en los Grados de Historia, Geografía e Historia del Arte y, mucho menos, en Educación Primaria, ¿cómo salir de esos tópicos y fronteras artificiales?

De los tópicos-estereotipos y fronteras artificiales sólo se sale con más estudio e información adecuada, crítica y actualizada. Es un problema tanto del estudiantado como del profesorado (como ya vimos en la pregunta 4). La formación básica de los futuros profesores (en las disciplinas referentes) es escasa, sobre todo en Educación Primaria, pero también en Secundaria. Lo ha sido y lo sigue siendo. Los conocimientos «referentes» cambian bastante y lo hacen también bastante rápido. Yo me creo lo de la formación continua a lo largo de la vida y llego a donde llego, a pesar de mi curiosidad científica y del mucho tiempo que, gustosamente, le dedico. Como dijo hace unos años Pilar Benejam: «Un docente/maestro 
nunca sabe suficiente». No hay que agobiarse excesivamente, pero hay que tener las cosas así de claras.

9. Peso de lo local y lo regional en ámbitos educativos no formales, compensa la visión centralista de la legislación educativa española? ¿Cuáles son las identidades que más le interesan al analizar la construcción de la historia y la enseñanza de la misma?

Eso lo tenemos bastante claro por los estudios realizados: los manuales de Secundaria dedican un 8-10\% o menos a lo local/regional (Fundación Bofill, 2001). No soy ni «regionalista» ni «españolista», pero creo que lo local/regional puede ser útil para formar ciudadanos con capacidad crítica: estudiar lo próximo también puede cumplir esa finalidad. También tendríamos que entender lo universal/global de manera menos europeizante/occidentalizante. No en vano el $80 \%$ de los contenidos de Historia, Geografía y Arte se dedican a ello y nada sabemos de África ni de Asia ni casi de las dos Américas (Oceanía no existe en los manuales). Las identidades, todas, tienen que ser razonables y no excluidoras y menos «asesinas», como dijo A. Maalouf (a las que habrá que combatir, vengan de donde vengan).

10. Desde la década de 1980 comienzan a surgir enfoques de la enseñanza de la historia que hacen hincapié en el método del historiador y en uso de fuentes históricas en el aula. Varios años después estos enfoques encuentran en estudios pedagógicos y psicológicos (constructivismo, Psicología Social, taxonomías de Bloom, etc.) un anclaje para proponer modelos de enseñanza de la historia con diferentes niveles de complejidad. ¿Cree que ese giro ha supuesto un vaciamiento disciplinar en la didáctica de la historia, o es algo inevitable?

No, yo no creo en un posible vaciamiento disciplinar en la didáctica de la Historia pues, al menos entre los didactas de la Historia, la cuestión del método y de la epistemología ha ganado terreno. Otra cosa son las aportaciones desde otras ciencias (Pedagogía, Psicología Básica) que, en función de su conocimiento de la Historia, pueden ser interesantes y ahí habría ejemplos positivos, indiferentes o negativos. 
Para poder ser un buen didacta de la Historia hay que ser también bueno en los saberes «referentes». De ahí la adquirida importancia de las didácticas especiales frente a otras didácticas generales, que sirven para otras cosas.

11. Frente a estas propuestas, que centran la enseñanza de la historia en elementos cognitivos, están surgiendo en el contexto europeo una respuesta conservadora que quiere volver al conocimiento de los principales hitos de la Nación como principal objetivo de aprendizaje. ¿Volverá a implantarse una enseñanza de la historia dedicada a consolidar una identidad nacional, puesta en duda por el empuje de fuerzas centrífugas del Estado español y la multiculturalidad europea?

Esta divergencia entre las principales finalidades (nacionalizadoras frente a críticas) del aprendizaje y enseñanza de la Historia es ya muy vieja. Se plantea en el siglo XVIII (Voltaire, por ejemplo) y continúa en el XIX y el XX (R. Altamira; las discusiones posteriores a la II Guerra Mundial o tras el Mayo del 68 parisino, con S. Citron; y en España desde finales de la década de 1970 y la siguiente, con Germanía 75, Cronos,...).

Los programas de la LOGSE (1991) eran menos nacionalizadores que los actuales post-2001, después del debate de las Humanidades. Seguimos ahí y los poderes públicos tienen más interés en una sociedad unificada en sus representaciones imaginarias, que en una sociedad más analítica y crítica. Como dijo un dirigente comunista de la extinta URSS: «la Historia es demasiado importante como para que la dejemos en manos de los historiadores». Y ahí seguimos estando, aunque nos pese y nos resulte insultante.

12. En relación al giro cognitivo de los estudios sobre la enseñanza de la historia, es visible también un distanciamiento entre los investigadores sobre enseñanza de la historia y los propios historiadores. ¿Cómo deberían colaborar más y mejor ambas figuras?

No comparto esa afirmación. Los didactas de la Historia y los historiadores, salvo excepciones poco abundantes, hemos tenido pocas relacio- 
nes y pocos intereses compartidos, desgraciadamente. Para entenderse con los historiadores hay que demostrar que también somos historiadores consistentes. Eso facilita las relaciones e intereses compartidos. Si no es así, entonces todo es más difícil. En Historia Contemporánea, por ejemplo, sí hay historiadores interesados (véase Ayer, 1998: Historia y sistema educativo, y hay más ejemplos).

Claro que si los didactas sólo somos cognitivistas, pues va a ser más difícil relacionarnos, lo cual no nos convendría mucho a todos. La didáctica de la Historia nació básicamente para la Educación Primaria, después pasó a la Secundaria y yo ya digo públicamente (en las Facultades de Historia) que ahora le toca el turno a las facultades. Ellos bromean sobre esta afirmación, pero ya no se sienten tan seguros o autosuficientes como hace años. El «giro cognitivista» no valdrá para casi nada si no va acompañado de una buena formación historiográfica. Una mejor y mayor presencia social-pública de los conocimientos históricos, del saber pensar históricamente, es algo que nos amalgama sabia y obligatoriamente a unos y a otros.

13. Cuanto más leemos y reflexionamos más dudas albergamos. ¿Está de acuerdo en que la historia debe enseñar a derribar estereotipos, sin caer en el relativismo ni el maniqueísmo? En ese sentido, ¿qué conceptos y coyunturas históricas le parecen más atractivos para ello?

Un cierto relativismo historiográfico y científico es indispensable en cualquier científico, de cualquier disciplina. En la actualidad, y ya desde la década de 1960 (Thomas Kuhn) y posteriormente (postestructuralismo), se ha venido defendiendo siempre, sabiendo que el conocimiento científico es histórico y provisional, aunque sea el mejor conocimiento de los humanos.

Lo del maniqueísmo es otra cosa y constituye «un pecado muy grave» para cualquier científico, especialmente para un historiador, para quien el multiperspectivismo es una base científica fundamental. También cualquier dogmatismo (de izquierdas o de derechas, igual me da) no es aceptable científicamente. 
Los conceptos y coyunturas históricas son atractivos en función de la finalidad que busquemos con la enseñanza de la Historia. Para mí cualquier coyuntura o período puede ser válido si está bien planteado, bien problematizado escolar y educativamente y tiene buenas actividades. Dicho eso, yo privilegiaría aquellos que afecten a mayor número de humanos y hayan sido más importantes para los debates actuales, intentando abordar, como se planteaba en la década de 1990, cuestiones sociales relevantes y cuestiones también candentes (como bién mostró Benoît Falaize, entre otros). Así como aquellos que nos ayuden a entender y practicar mejor la interculturalidad, tanto desde instancias locales, regionales, como estatales, europeas, mundiales realmente globales, etc. Lo globolocal o locoglobal: por ejemplo, la Neolitización (mundial, no sólo Oriente Medio); los procesos deslocalizadores (desde Grecia hasta hoy); la historia de la alimentación; los grandes cambios sociales (América, industrialización); la historia de los conflictos religiosos; colonialismos y postcolonialismos; la historia de la vida cotidiana y de los géneros; religión y disciplina-represión social y política; poder político (democracia y dictadura), etc.

14. Teniendo en cuenta estas reflexiones previas sobre los libros de texto, la metodología docente y la trayectoria que ha seguido la didáctica de la Historia entre el enfoque cognitivo y la construcción de identidades colectivas, si tuviese que proponer varios temas clave sobre los que realizar una tesis doctoral sobre la enseñanza de la historia, ¿cuáles serían y por qué?

Ya he citado una posible tesis doctoral: «Cénit y ocaso de la innovación educativa histórica a través de sus manifestaciones escritas o no (manuales, cuadernos escolares, relatos de vida, etc...)». Otras posibles abordarían temas que yo considero aún poco trabajados, como por ejemplo:

- El pensamiento de los docentes sobre las finalidades que ellos otorgan a la enseñanza-aprendizaje de la Historia, no tanto teóricamente sino en su práctica diaria y su contraste con la práctica real en las aulas. Eso habría que hacerlo con los docentes «seniors» y con los más recientes (salidos ya del Máster de Secundaria). 
- La preparación «referencial» de los alumnos del Máster de Secundaria y sus conocimientos en Historia, Geografía y Arte. Igual nos llevamos sorpresas profundas y duras.

- Sobre la argumentación (presente o ausente) en los manuales de Historia y también sobre el uso inducido de las imágenes (ya sabemos algo, pero habría que profundizar más).

- Sobre las dificultades y temores del profesorado respecto de la innovación (en cualquiera de sus múltiples dimensiones).

- Sobre las influencias mutuas (o no) de las didácticas de la Historia internacionales (europeas, americanas y otras). Eso tendría muchas posibles ramificaciones, pero no sabemos casi nada en concreto. Se podría empezar por cuantificar las citas y lecturas, así iríamos profundizando más y podríamos intentar buscar formas de mayor interrelación (como ya hacen los didactas de las Ciencias Experimentales, nosotros aún no hemos llegado a eso).

- Todas las cuestiones relacionadas con la «sociogénesis» y el «código disciplinar» son básicas y requieren más investigaciones. En eso soy muy "fedicariano», aunque sea casi el único dentro del staff académico de didáctica de la Historia y lo he defendido públicamente y por escrito; eso fue un regalo de los colegas fedicarianos, que en otros aspectos no aprecio tanto, pero en lo de la «sociogénesis e historia de las disciplinas escolares» fueron una bendición científica.

- Ya hemos constatado la «invisibilidad de las mujeres» en la enseñanza de la historia, ese era el primer paso, pero ahora nos faltan dos más: hacer real su presencia en la enseñanza y, sobre todo, generar una enseñanza de la historia desde la mixité, desde una perspectiva normalizada de la coexistencia/convivencia de los humanos, hombres y mujeres, tal cual somos o deberíamos ser, esto es, desde la igualdad y no desde la discriminación.

- Y muchas otras cosas más, pero creo que con eso ya tenemos cosas para un decenio: ¡Suerte y adelante! 


\section{SELECCIÓN DE OBRAS DE RAFAEL VALLS MONTÉS}

- La interpretación de la historia de España y sus orígenes ideológicos, en el bachillerato franquista (1938-1953) (Valencia: Universidad Literaria-ICE, 1984).

- La derecha regional valenciana: el catolicismo político valenciano (1930-1936) (Valencia: Institut Alfons el Magnànim, 1992).

— «Las imágenes en los manuales escolares españoles de Historia, ¿ilustraciones o documentos?», Íber: Didáctica de las ciencias sociales, geografía e historia, 4 (1995): 105-119.

- «Los usos de la historia enseñada y la reciente polémica en España: un enfoque didáctico», Ayer, 30 (1998): 221-240.

- «Sobre la elección y usos de las imágenes de los manuales escolares de historia: un ejemplo español (1900-1998)», Clío y asociados. La historia enseñada, 4 (1999): 77-100.

- (con Verena Radkau García) «La didáctica de la historia en Alemania: una aproximación a sus características», Íber: Didáctica de las ciencias sociales, geografía e historia, 21 (1999): 89-106.

- «Los materiales curriculares de Fedicaria», Cuadernos de Pedagogía, 295 (2000): 68-70.

- «Los estudios sobre manuales escolares de historia y sus nuevas perspectivas», Didáctica de las ciencias experimentales y sociales, 15 (2001): 23-36.

- (Con Daniel Gil Pérez y Amparo Vilches Peña) «¿Es necesaria una contrarreforma educativa?», Alambique: Didáctica de las ciencias experimentales, 29 (2001): 119-123.

- "Història i ciències socials als llibres de text», L'Avenç: Revista de història i cultura, 261 (2001): 42-44.

- (Con Alfredo López Serrano, coords.) Dimensión europea e intercultural en la enseñanza de las ciencias sociales (Madrid: Síntesis, 2002).

- (Con Alberto Sabio Alcutén, Carlos Forcadell Álvarez, Ignacio Peiró Martín, Gonzalo Vicente Pasamar, coords.) Usos de la historia y políticas de la memoria (Zaragoza: Universidad de Zaragoza, 2004). 
- (Coord.) Los procesos independentistas iberoamericanos en los manuales de historia (Madrid: Fundación Maprfre Tavera-OEI, 2005).

- Historiografía escolar española: siglos XIX-XXI (Madrid: UNED, 2007).

- «La enseñanza de la Historia en España: la compleja construcción de un saber escolar (1846-2006)», Bulletin d'histoire contemporaine de l'Espagne, 43 (2007): 161-181.

- Enseñanza de la historia y textos escolares (Buenos Aires: Libros del Zorzal, 2008).

- Historia y memoria escolar. Segunda República, Guerra Civil y dictadura franquista en las aulas (Valencia: PUV, 2009).

- «La presencia del Islam en los actuales manuales españoles de historia", Íber: Didáctica de las ciencias sociales, geografía e historia, 70 (2011): 59-66.

— «La Institución Libre de Enseñanza y la educación histórica: Rafael Ballester y la renovación historiográfica y didáctica españolas de inicios del siglo XX», Historia de la Educación: Revista interuniversitaria, 31 (2012): 231-256.

- (Con David Parra Monserrat) «Libros de texto: una visión simplificada», Íber: Didáctica de las ciencias sociales, geografía e historia, 85 (2016): 15-19.

\section{Nota sobre los autores:}

Cosme J. Gómez Carrasco es Licenciado en Humanidades y Doctor en Historia Moderna por la Universidad de Castilla-La Mancha. Actualmente es Profesor Contratado Doctor de Didáctica de las Ciencias Sociales en la Universidad de Murcia (acreditado como Profesor Titular desde 2013). Ha sido becario predoctoral en la Universidad de Castilla-La Mancha (20042007), becario posdoctoral en la EHESS de París (2008-2009), e investigador posdoctoral en el Instituto de Historiografía Julio Caro Baroja de la Universidad Carlos III de Madrid (2009-2010). Además ha sido investigador visitante en el Instituto Europeo de Florencia (2006), Profesor Invitado en el Centre de Recherches Historiques de París (2015) y Honorary Researcher Associate en la University College of London - Institute of 
Education de Londrés (2016). Sus líneas de investigación versan sobre evaluación del pensamiento histórico, formación docente, manuales escolares y epistemología histórica. Ha coordinado siete monográficos en revistas de Brasil, Colombia y España. Entre sus publicaciones destacan siete libros como coeditor, por ejemplo La formación del profesorado en Educación Infantil y Primaria: retos y propuestas (2014); La Edad Moderna en Educación Secundaria. Propuestas y experiencias de innovación (2016). Algunos de sus artículos son: "Los contenidos de ciencias sociales y las capacidades cognitivas en los exámenes de tercer ciclo de Educación Primaria ¿Una evaluación por competencias?», Revista Complutense de Educación, 24 (1), (2013): 91-121; "Historical skills in compulsroy education: Assesment inquiry based strategies and students' argumentation», NAER, 5 (2), (2016): 130-136.

Raimundo A. Rodríguez Pérez es Licenciado en Historia, Doctor en Historia Moderna y Profesor Contratado Doctor de Didáctica de las Ciencias Sociales en la Universidad de Murcia (acreditado como Profesor Titular desde 2015). Ha sido becario predoctoral del Ministerio de Educación y la Fundación Séneca. Actualmente es coordinador del Grado en Educación Primaria de la UMU. Imparte docencia en dicho grado y en el Máster de Investigación e Innovación en Educación Infantil y Primaria. Sus líneas de investigación se centran en la formación docente, la evaluación y las metodologías didácticas en Educación Primaria y Secundaria. Entre su más de medio centenar de publicaciones destacan tres libros como coeditor: Investigación e innovación en Educación Infantil (2014); Innovación y enseñanza en Educación Primaria (2015); La Edad Moderna en Educación Secundaria. Experiencias de investigación (2016). De los artículos cabe subrayar: "La enseñanza de la Historia en Educación Primaria y la construcción de una narrativa nacional. Un estudio sobre exámenes y libros de texto en España», Perfiles Educativos, 150 (2015): 20-38; «La Historia Social de la familia en España y su repercusión en la Didáctica de las Ciencias Sociales», Tempo e Argumento, 6 (11), (2014): 54-77. 